\title{
Defining functional roles for research institutions in helix innovation networks
}

\author{
Florian Schütz ${ }^{1 *}$ Fabian Schroth ${ }^{1}$, Antonia Muschner ${ }^{1}$, Martina Schraudner ${ }^{1}$
}

Abstract: This paper presents an empirically grounded case-based analysis of quadruple helix innovation networks. On the basis of qualitative interviews with representatives of 16 heterogeneous networks, we investigate the functional network roles of 172 actors from the fields of academic research, business, government and society. In this article we focus on universities and research and technology organisations, which face the challenge of having to redefine their functional roles and unique value in the face of increased diversification of knowledge sources within current quadruple helix innovation systems. We delineate both existing and potential future roles for academic actors using a typology of functional roles, and present the challenges research establishments must meet in order to fulfil these roles successfully. Finally, we outline the implications of this analysis for the strategic positioning of research institutions, so as to ensure the future inclusion of their innovative capacity in collaborative innovation networks.

Keywords: quadruple helix innovation; networks; innovation networks; functional roles; roles in networks; qualitative study; microstudy; network analysis; universities; research and technology organisations

Submitted: July $18^{\text {th }}, 2018$ / Approved: November $14^{\text {th }}, 2018$

\section{Introduction}

Scholars increasingly conceptualise innovation systems as a multiple helix (Carayannis and Campbell, 2009; Etzkowitz and Leydesdorff, 2000). This kind of model reflects the increasing complexity of knowledge creation and diffusion. It assumes that multi-actor innovation systems rely on the dynamic and flexible interaction of diverse elements, rather than on a number of synchronised, stable processes.

The quadruple helix $(\mathrm{QH})$ model in particular focusses on the interaction of four major subsystems in knowledge-driven innovation systems, namely academic research, business, government, and society. This model acknowledges that successful research and innovation depend not only on intra-organisational activities, but also on collaboration among businesses, research establishments, government actors and the public.

Figure 1 Quadruple Helix Innovation Systems. Visualisation @ Fraunhofer CeRRI

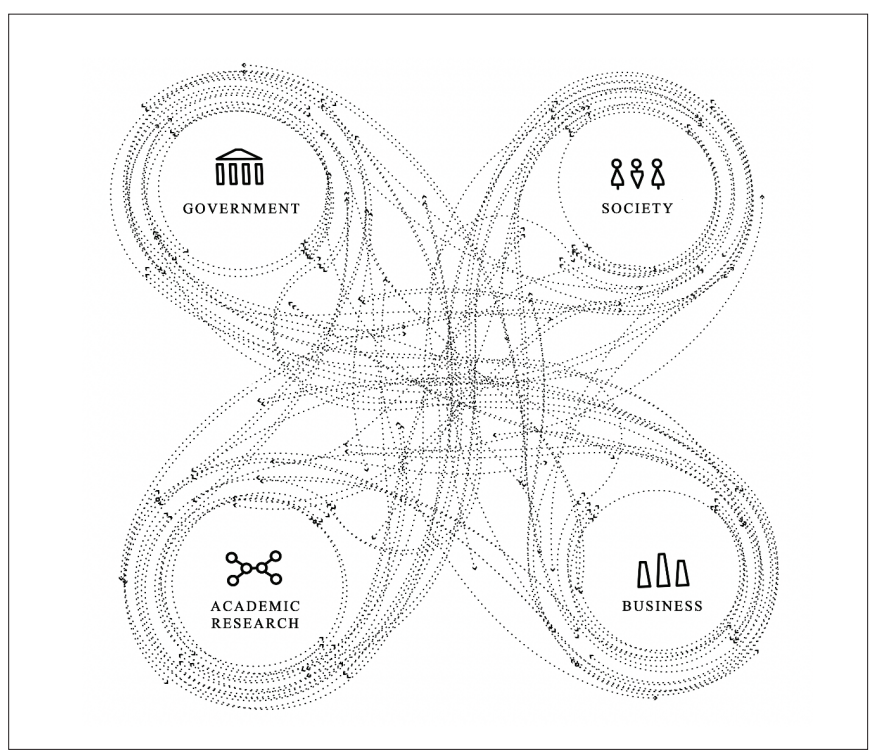

On a micro level, this collaboration takes place in networks composed of actors from the aforementioned different subsystems. Official acknowledgement of the advantages and requirements of multi-actor collaborative innovation is reflected in the increased support for multi-actor projects on the part of both national and international research funding bodies and policymakers. In view of these developments, research establishments specialising in either basic or applied research need to bring their strategies and goals in line with transdisciplinary and collaborative forms of innovation.

Furthermore, following Gibbons et al. (1994), knowledge is no longer produced solely within academic institutions, but also by heterogeneous groups of actors in a variety of contexts, through so-called mode 2 knowledge production. The unique role of the academic sector is therefore becoming increasingly indeterminate. For research establishments used to working in linear push-pull models, responding to this changing context presents a nontrivial challenge.

This is further exacerbated by the fact that it is currently unclear how and to what extent the innovative potential of various actors - in particular research institutions, small and medium-sized enterprises (SMEs) and societal actors - can be meaningfully integrated into multiple helix innovation networks. It is likewise not clear how costs, risks, benefits and opportunities can or should be distributed between the actors in accordance with their respective roles.

Answering these questions requires a clearer understanding of the qualitative and functional aspects of existing roles in $\mathrm{QH}$ innovation networks. This would in turn shed light on the challenges faced by traditional academic actors, which in Germany can be divided into two subcategories. Firstly, there are four major public research institutions with missions ranging from the furtherance of basic research to the advancement of applied research for the development of products and processes. The second category consists of higher education institutions such as universities, which in addition to conducting research are also providers of education.

(1) Fraunhofer IAO, Center for Responsible Research and Innovation (CeRRI), Hardenbergstraße 20, 10623 Berlin, Germany

* Corresponding author: florian.schuetz@iao.fraunhofer.de 
As the functional roles of academic actors within $\mathrm{QH}$ networks are particularly under-investigated, they form the focus of our study, in which we ask the following question: Which functional roles exist in $\mathrm{QH}$ innovation networks for actors in the academic sector?

In the following sections we present a literature review, our methodological approach and our empirical findings.

\section{Literature review and theoretical framework}

The existing literature on $\mathrm{QH}$ innovation networks focusses primarily on the macro level, i.e. on national or regional innovation systems (Carayannis and Campbell, 2012). Innovation processes in these networks are described as dynamic and flexible, and marked by the interaction of a multitude of actors representing business, government, academic research and civil society - leading to innovations that are particularly capable of addressing and solving societal problems.

A central aspect of the $\mathrm{QH}$ model of competitive innovation is socalled mode 3 knowledge, which is based on the ability to combine various bodies knowledge and perspectives on innovation in a manner that integrates the existing expertise and knowledge production dynamics of all actors involved. It entails the continued co-existence of other modes of knowledge production, which continue to evolve through mutual influence - for instance when traditional academic research (mode 1) is used in conjunction with transdisciplinary research (mode 2). Mode 3 contains inter- and transdisciplinary forms of knowledge production, during which existing bodies of knowledge and modes of knowledge production are maintained and harnessed for innovation. It is only through this preservation of plurality that the mutual enrichment of different bodies of knowledge becomes possible. Three processes are critical in this respect, namely "co-evolution", or joint development and mutual adaptation, "co-specialisation", i.e. joint and coordinated specialisation, and "co-opetition", which is a productive duality of competition and cooperation (Carayannis and Campbell, 2006; 2009; Carayannis et al., 2012). The successful integration of the various modes and bodies of knowledge is seen as fundamental to the development of sustainable national innovation ecosystems (ibid.).

The QH model increasingly informs official research and innovation policy, as well as the development of national and regional innovation systems (McAdam and Debackere, 2018). At the same time, little has been written about the challenges and possibilities QH innovation networks hold for traditional actors such as research establishments - which is surprising, especially in light of the aforementioned new mode of knowledge production lying at the basis of these networks. For traditional academic actors, the changing demands of knowledge production, coupled with increased integration of societal actors in innovation processes, can be expected to result not only in new challenges and opportunities, but in fact new roles within the innovation process.

One approach to understanding these challenges and the complexity of QH networks is case-based microanalysis. The insights gained through this type of enquiry are crucial to the future practical design of such networks (Miller et al., 2018). Early case-based microanalyses of QH networks investigate their evolution from triple helix networks, focussing in particular on the roles actors from different sectors play in their creation. Thus Arnkil et al. examine how in creating and furthering $\mathrm{QH}$ networks, government actors occupy the role(s) of "enabler", "decision maker", "supporter", "utiliser", "developer", "marketer" and/or "quality controller" - depending on the structure of the network in question (Arnkil et al., 2010). A central question in these studies is how the fourth helix, namely society, can be integrated into existing triple helix innovation networks. Accordingly, Lindberg et al. (2014) examine how NGOs can incorporate civil concerns into existing networks, and look at the challenges they face in doing so. Cunnhigham et al. (2017) show how individual academic researchers can achieve a similar result by means of boundary spanning. Nordberg (2015) in turn focusses on a single research institution to show how it can use its position at the intersection of academic research and government to open up existing triple helix networks to social actors.

All of the above entails changes and shifts in the roles played by classical innovation actors. Academic institutions are no longer the sole providers of research and education; local government, for example, can also fulfil this function. No longer exclusive providers of cuttingedge knowledge, research establishments instead increasingly corroborate knowledge developed by other actors (MacGregor, 2010).

In short, the existing literature shows that knowledge production, innovation systems and the roles of innovation actors are all changing. On the one hand, it is argued that research establishments are no longer the exclusive producers of knowledge in $\mathrm{QH}$ networks. On the other hand, academic actors are increasingly seen to perform the function of interfacing the other three sectors for the sake of integration into innovation networks. This paper expands upon this exploration of roles in $\mathrm{QH}$ innovation networks by means of the empirical investigation presented below.

\section{Methodology}

The aim of our micro study was to gain a thorough understanding of how cooperation among different actors in QH innovation networks is structured, via a differentiated analysis of the functions and roles of the actors in selected QH networks. As the goal was the discovery and thorough understanding of new types of functional roles, we chose to conduct our research in the form of a qualitative case study adhering to the principle of openness (Flick et al., 2010; Lamnek, 2010).

A qualitative sampling scheme (Merkens, 2010) was used to identify 16 different networks as cases for the study; the relevant criteria being the number of actors from each of the four subsystems, and the degree of innovativeness of the project in question. We aimed to achieve a diverse distribution of actors from different subsystems in our sample, in order to recreate the quadruple helix on a micro level. We furthermore looked for networks initiated by actors of different subsystems so as to allow for a wider variety of possible role types within 
the sample, continuing until theoretical saturation was reached. The respective projects of the selected networks cover a wide range - from social innovations such as sustainable mobility solutions, to the development of new technological devices.

Each of the participating networks was asked to nominate one to three representatives, with whom semi-structured and problem-centred interviews of about 90 minutes each were conducted. As a means of systematically gathering information about the various relationships within the networks, each interviewee was asked to create a so-called network map (Straus, 2010; Wolf, 2006). The aim was to have interviewees create visual representations of their respective networks, to serve as a powerful speaking prompt and offer a basis for methodical discussion of the network in question. The first step was to elicit the names of network participants that play an important part in the innovation process, by means of a name generator: respondents were given stickers on which to write the names of the relevant organisations, and were asked to be as precise as possible in each case. They then placed these stickers on a network map template prepared by the research team, thereby revealing the position of the various actors within the network from their perspective. The interviewees themselves could determine the number of alters, and there was no prescribed time frame (e.g. by limiting alters to actors with whom they had dealings within the last three months). The practical advantage of this methodological approach is that the network ego - not the interviewee as individual, but rather the organisation - determines the borders of the network. Once the alters had been named, respondents were given stickers with follow-up questions that functioned as name interpreters. These questions dealt with roles, opportunities, risks and tasks; the aim being to arrive at a detailed description of each named alter in terms of each of these characteristics.

In conjunction with the network maps drawn up by the interviewees, a pre-prepared interview guide was used to structure the interviews around questions regarding the actors within the network, and the distribution of roles, opportunities and risks. The interview guide was developed on the basis of the theoretical framework and research question as presented in section 2 above.

The interview records were transcribed and the relevant information was extracted and ordered by means of qualitative content analysis (Mayring, 2010). Within the 16 networks, a total of 172 actors could be identified. The interviewees' analyses of the actors in their respective networks resulted in a total of 239 descriptions of distinct roles, which were labelled using in vivo coding. The reason this number exceeds that of the actors themselves is that single actors can occupy more than one role. Said roles were defined in terms of several dimensions, namely the actors' functions within the network, their unique value proposition, means of collaboration, and their input and output in the network. In addition, the nature of the actors in each of these roles was noted, as well as their respective positions within the quadruple helix. The next step was to reduce the abovementioned 239 role descriptions to 26 typical functional roles, following Kluge's (2000) approach to typology construction.
Accordingly, the functional roles presented below should be understood as generalised types. Although individual cases may deviate from these types in one or more respects, they remain useful in understanding and explaining the collaborative interaction of actors in QH networks.

\section{Findings: Functional Roles for Research Institutions in Quadruple Helix Innovation Networks}

Below we present our findings, focussing on the academic strand of the quadruple helix - i.e. on universities and research and technology organisations (RTOs). The current diversification of knowledge sources places these institutions in the challenging position of having to (re-)define their functional role within QH or mode 3 innovation networks. In the presence of other knowledge providers (such as startups and open innovation labs), academic actors need to make clear what they bring to the table - while also considering what new roles they might occupy in future innovation networks.

\section{Research institutions as major actors}

Within collaborative QH innovation networks, RTOs and universities can take up the role of "knowledge generator". In nearly all of the networks we examined, this role was played by individuals and institutions from the academic sector (with one exception, where the role was instead taken up by a business actor). "Knowledge generators" differ from other types of knowledge providers in that their primary contribution to the network consists not in pre-existing expertise, but rather the creation or development of new knowledge. Two aspects of this role stood out in the networks we analysed. Firstly, there is virtually no direct or active collaboration between these and other actors within the quadruple helix. Instead, "knowledge generators" carry out their work autonomously and then present the newly-developed knowledge to the network as a finished product. Strictly speaking, the autonomous nature of this functional role stands in contradiction to mode 3 knowledge production, which should actually form the basis of a $\mathrm{QH}$ network.

Secondly, it is worth noting that the main perceived benefit of "knowledge generators" is not know-how, but rather the abundant workforce academic institutions typically have at their disposal. In fact, when they become active in innovation networks, it is the "knowledge generators" themselves that primarily tend to benefit from the know-how of other actors. Participation in innovation networks moreover helps research institutions procure funding, improve their standing and expand their own professional networks, while providing the participating academic personnel with opportunities for further qualifications.

Integrating "knowledge generators" into collaborative innovation processes is seen as difficult. According to our respondents, dealing with the issue of intellectual property is a major challenge. The pace at which academic institutions tend to operate - which the respondents often juxtaposed with the work approach of the business sector - was likewise noted to be a potential hindrance to collaboration. 
As providers of specialised knowledge, universities and RTOs can play the role of "knowledge supplier". This, in turn, can take two forms: "specialists" have the necessary expertise to deal with particular issues, whereas "contextualisers" are able to use their overview of particular fields to address issues within a broader academic or scientific context. In the networks we examined, however, "specialists" from the business sector noticeably outnumbered their counterparts from the academic sector. The "contextualisers", however, were exclusively academic actors - albeit individual lecturers or senior researchers, as opposed to institutions.

Actively involving academic "knowledge suppliers" in innovation networks is seen as difficult. It is in the first place not easy to find the right people for the role within the academic sector. Secondly, the role's compensation model poses its own set of challenges. The "specialists" and "contextualisers" in the analysed cases contributed their know-how not as permanent and active network members, but rather through voluntary participation in workshops. Accordingly, these actors did not consider being a "knowledge supplier" as part of their basic professional responsibilities. Rather, it was seen as an additional personal investment of time and labour, usually without financial compensation. On the other hand, this role presents academic professionals with new opportunities for knowledge exchange, and can lend added credibility to their work.

Academic actors can furthermore assume the roles of "incorruptible" and "validator". In contrast to "knowledge supplier", these roles are predicated not on expertise, but rather on academic reputation and the accordant ability to give the network's collaborative innovation processes a scientific seal of approval. "Validators" confirm the network's adherence to scientific quality standards, whereas "incorruptibles" help the network project an independent stance to the outside world, e.g. to the target users of the product, service or technology under development. Since business and societal actors are often seen as motivated by self-interest, academic institutions (or their representatives) are at a distinct advantage in this role. The integration process and compensation model for both of these roles, however, entail the same difficulties as in the case of "knowledge suppliers".

A network's "negotiators" facilitate contact and cooperation with a range of different corporate and legal entities within the innovation system. Universities and RTOs that take on this role do so mainly through procuring public funding for the network.

\section{Strong competition for research institutions}

"Interaction enablers" effectively form the hub of the network, establishing links between the various network actors and ensuring that the methods and processes needed for effective transdisciplinary collaboration are in place. They play a central role in intra-network communication, liaising or mediating between the various heterogeneous stakeholders - including in the case of different or conflicting interests, e.g. with respect to intellectual property. In the examined cases, this role was taken up by a variety of actors from each of the four sectors of the quadruple helix: large-scale enterprises, SMEs, startups, business funding agencies, hubs and incubators, government institutions, civil organisations and stakeholders, and - last but not least - RTOs and universities. Despite its aforementioned complexity, the function of "interaction enabler" is seen as primarily labour-intensive, rather than dependent on particular specialist knowledge. This explains why nearly all actors within the quadruple helix are able to assume this role.

It is difficult to define the role's compensation model on the basis of the observed cases. In many instances, its financial viability was solely tied to public funding, and not based on jointly generated revenue flowing back into the network. Still, as in the case of "knowledge generators" and "knowledge suppliers" above, actors from the academic sector stand to benefit from the role of "interaction enabler" via an increase in know-how from other network members, the opportunity to forge contacts within the field of innovation, an improved academic reputation, and added credibility.

"Network strategists" carry out a similar function, in that they provide structure to intra-network collaboration. In contrast to "interaction enablers", however, they do so not by directly enabling or overseeing collaborative processes, but rather by determining the network's overall strategy and ensuring that it is followed by all participating parties. They focus on the big picture and have little involvement in the network's day-to-day operations. Though this role was seldom present in the examined cases, "network strategists", like "interaction enablers", could be found in all four sectors of the quadruple helix.

"Pioneers" perform a function that was long the sole preserve of academic or scientific research, namely conducting cutting-edge innovation that makes use of the very latest available methods and technologies. Given that basic research and exploratory research (within the field of applied research) are among the basic tenets of the academic sector, academic actors should be well-equipped for this role. Nevertheless, in the networks we examined, all of the "pioneers" bar one (a university professor) belonged to the business sector, with the majority of the "pioneering" work carried out by established corporations and startups. This is in keeping with a current general trend, whereby corporate-startups partnerships constitute a significant source of innovative products and services.

In contrast to the practice of bilateral mergers and acquisitions in the business sector, there is as of yet no well-developed formula for integrating "pioneers" into QH networks. The issue of intellectual property often stands in the way of such collaboration, and for the corporations and startups standing at the forefront of innovation, opportunities for exchange and professional network development do not suffice as incentives for collaboration.

A similar picture arises with respect to the "thought leaders" that are responsible for most of the actual innovation within the network. In contrast to "pioneers", "thought leaders" are not defined by their cutting-edge knowledge or breakthrough ideas, but rather by their innovative mindset. As in the case of "pioneers", universities and RTOs are no longer the primary "gatekeepers" to the coveted "thought leaders". In the analysed networks, this role was mainly occupied by actors from the business sector (hubs and incubators) and from the civil 
sector (NGOs). The integration of "thought leaders" or their "gatekeepers" into innovation networks presents the same challenges as in the case of "pioneers".

\section{Potential future roles for research institutions}

In our analysis, we discovered two further major functions that universities and RTOs should be capable of performing in future, despite their not assuming these roles in the networks we investigated. The network's "public face" helps the network or innovation attain greater and wider visibility. These actors can use their position in the public eye to convey innovative outcomes to particular target groups. In the examined cases, this role was mostly played by large corporations or government actors. Academic institutions could nonetheless leverage their prestigious status to the same effect.

"Business model developer" is another role that was seen as crucial by many of our respondents. "Business model developers" know how to translate the results of the network's collaborate efforts into concrete, packaged solutions that are of clear value to particular target groups and framed within a suitable business model. Many of the respondents in our study cited the lack of a business model mindset within the academic sector as a reason for preferring the business and civil sectors as sources of innovative potential. Nonetheless, this role holds significant potential for the academic sector: in taking over the function of "business model developer", academic actors could further cement their position within QH networks.

\section{Conclusion and discussion}

In moving beyond the largely theoretical discussion of QH innovation networks in the existing literature, the above analysis provides a better understanding of how these networks function in practice, while shedding light on certain particularly pertinent challenges. By means of a typology of functional roles, network structures and preconditions for multi-actor collaboration within a quadruple helix can be more thoroughly understood - which places actors from all four subsystems in a better position to manage their collaboration in existing $\mathrm{QH}$ networks.

Research establishments in particular stand to benefit from a deeper understanding of collaboration practices and roles in $\mathrm{QH}$ innovation networks. Currently, traditional roles played by universities and RTOs continue to inform the relationship between the academic sector on the one hand and the business sector or market on the other. Established collaboration models, for example contract research on behalf of companies, still adhere to a push-pull conception of innovation. It is, however, becoming increasingly important for research institutions to redefine their functional role within in the innovation system and to delineate the unique value they bring to the table. Only in so doing can they develop future-proof strategies in response to the growing prominence of knowledge sources outside of the academic sector.

Our study shows that universities and RTOs already occupy a variety of roles within $\mathrm{QH}$ networks. In some of these roles, academic institutions dominate, whereas in other instances they face strong competition from the other sectors and find it difficult to clarify their unique value proposition with respect to the network.

When it comes to the development of new knowledge, our study reveals research institutions to be in a strong position as "knowledge generators". Nonetheless, knowledge generation should in future become a more collaborative process; one that is more closely integrated with the rest of the network. If research establishments are to engage in true mode 3 knowledge production, they cannot merely contribute their own academic knowledge to the network, but have to facilitate the collaborative development of new knowledge. In other words, they additionally need to assume the role of "interaction enabler" wherein they face competition from actors from the other three sectors of the quadruple helix. In order to cement their unique value as future "interaction enablers", research institutions should work on redefining the role, so that it is not seen as merely or primarily labourintensive. Rather, the focus should shift to the extensive specialised knowledge needed in implementing effective transdisciplinary work processes and methods, and facilitating communication between actors from different fields. Said specialised knowledge could be developed and established within the academic sector. Thus - and by furthermore assuming the roles of "incorruptibles" and "validators" - universities and RTOs can use the diversification of knowledge sources to their advantage. Far from merely staving off redundancy, they can in fact significantly strengthen their position as indispensable actors within the innovation process.

As "knowledge suppliers" - or more precisely as "specialists" - academic actors face strong competition from the business sector. Furthermore, the conventional role of research institutions is called into question by the fact that virtually all of the "pioneers" in the observed networks are corporations and startups. If the academic sector is to gain ground in collaborative innovation, its basic mindset needs to shift and new modes of knowledge and technology transfer must be created. Only then will "thought leaders" from research institutions be able to take centre stage in $\mathrm{QH}$ networks. In addition, research institutions need to address the shortcomings that have been ascribed to them in their role as "knowledge suppliers" - namely the difficulty in gaining access to the right "specialists", the slow pace of academic research, and the as of yet unresolved issue of intellectual property in open innovation ecosystems.

Innovation networks increasingly turn to the business sector for expertise, especially in the field of technology, since technology experts with a business background bring the combination of a sound understanding of the latest technology and a business model mindset to the table. Research institutions could in future likewise present their knowledge as packaged solutions, framed by workable business models. This can be achieved through interdisciplinary collaboration (in particular by drawing more strongly on the social sciences) and by rethinking the distribution of tasks within knowledge and technology transfer.

Finally, research institutions and funding bodies face the task of defining new compensation models for the inclusion of academic actors in $\mathrm{QH}$ networks. In the analysed networks, academic professionals were 
often invited to share their expertise on a one-off basis, e.g. through participation in workshops. For this they received no financial remuneration; instead, they were rewarded for their time and effort with the opportunity to forge new professional contacts. Beyond that, however, there is still the need for a sustainable compensation model - not only with respect to research institutions, but also for societal stakeholders and startups. Ultimately, all participating actors should be rewarded for the value they contribute to the network, through a proportionate share in the results of the collaborative innovation process. It must, however, be kept in mind that the academic sector operates in accordance with a different value system than business or civil society. As long as career success and pro rata compensation in the academic sector are measured in the number of publications under one's name and the amount of funding one has procured, these likewise remain the most important determiners of fitting compensation for academic actors involved in innovation networks.

In short, research institutions face the major task of strategising for the leap from bilateral push-pull cooperation to quadruple helix collaboration. An understanding of the major functional roles within $\mathrm{QH}$ innovation networks opens up the possibility for actors from the academic sector to take up or more effectively perform those roles. This in turn affords these organisations the chance to tap into immense potential - not only to their own benefit, but so as to improve the overall quality of collaborative innovation.

\section{References and Notes}

Arnkil, R., Järvensivu, A., Koski, P. and Piirainen, T. (2010), Exploring Quadruple Helix: Outlining user-oriented innovation models, Työraportteja Working Papers, Tampere.

Bundesministerium für Bildung und Forschung (BMBF) (2010), Ideen. Innovation. Wachstum: Hightech-Strategie 2020 für Deutschland, [Ideas. Innovation. Prosperity. High-Tech strategy 2020 for Germany], Bonn, Berlin.

Carayannis, E.G., Barth, T.D. and Campbell, D.F.J. (2012), “The Quintuple Helix innovation model. Global warming as a challenge and driver for innovation", Journal of Innovation and Entrepreneurship, Vol. 1 No. 1, pp. 2-12.

Carayannis, E.G. and Campbell, D.F.J. (2009), “'Mode 3' and 'Quadruple Helix': toward a 21st century fractal innovation ecosystem", International Journal of Technology Management, Vol. 46 No. 3/4, pp. 201-234.

Carayannis, E.G. and Campbell, D.F.J. (2012), "Mode 3 Knowledge Production in Quadruple Helix Innovation Systems", in Carayannis, E.G. and Campbell, D.F.J. (Eds.), Mode 3 Knowledge Production in Quadruple Helix Innovation Systems, Springer New York, New York, NY, pp. 1-63.

Cunningham, J.A., Menter, M. and Young, C. (2017), "A review of qualitative case methods trends and themes used in technology transfer research", The Journal of Technology Transfer, Vol. 42 No. 4, pp. 923-956.
Etzkowitz, H. and Leydesdorff, L. (2000), “The dynamics of innovation: from National Systems and "Mode 2" to a Triple Helix of university-industry-government relations", Research Policy, Vol. 29 No. 2, pp. 109-123.

European Commission (EC) (2011), The Communication from the Commission to the European Parliament, the Council, the European Economic and Social Committee and the Committee of the Regions: Horizon 2020 The Framework Programme for Research and Innovation, Brussels.

Flick, U., von Kardorff, E. and Steinke, I. (Eds.) (2010), Qualitative Forschung: Ein Handbuch, 8th ed., Rowohlt, Reinbek.

Gibbons, M., Limoges, C., Nowotny, H., Schwartzman, S., Scott, P. and Trow, M. (1994), The New Production of Knowledge. The Dynamics of Science and Research in Contemporary Societies, Sage Publications, London.

Gläser, J. and Laudel, G. (2009), Experteninterviews und qualitative Inhaltsanalyse: Als Instrumente rekonstruierender Untersuchungen, 3rd ed., VS Verlag für Sozialwissenschaften, Wiesbaden.

Kluge, S. (2000), "Empirisch begründete Typenbildung in der qualitativen Sozialforschung”, Forum Qualitative Sozialforschung, No. 1. Lamnek, S. (2010), Qualitative Sozialforschung: Lehrbuch, 5th ed., Beltz, Weinheim, Basel.

Lindberg, M., Lindgren, M. and Packendorff, J. (2014), "Quadruple Helix as a Way to Bridge the Gender Gap in Entrepreneurship. The Case of an Innovation System Project in the Baltic Sea Region", Journal of the Knowledge Economy, Vol. 5 No. 1, pp. 94-113.

MacGregor, S.P., Marques-Gou, P. and Simon-Villar, A. (2010), "Gauging Readiness for the Quadruple Helix. A Study of 16 European Organizations", Journal of the Knowledge Economy, Vol. 1 No. 3, pp. 173-190.

Mayring, P. (2010), Qualitative Inhaltsanalyse. Grundlagen und Techniken, Beltz, Weinheim, Basel.

McAdam, M. and Debackere, K. (2018), “Beyond 'triple helix' toward 'quadruple helix' models in regional innovation systems. Implications for theory and practice", R\&D Management, Vol. 48 No. 1, pp. 3-6.

Merkens, H. (2010), "Auswahlverfahren, Sampling, Fallkonstruktion", in Flick, U., von Kardorff, E. and Steinke, I. (Eds.), Qualitative Forschung: Ein Handbuch, 8th ed., Rowohlt, Reinbek, pp. 286-299.

Miller, K., McAdam, R. and McAdam, M. (2016), "A systematic literature review of university technology transfer from a quadruple helix perspective. Toward a research agenda", R\&D Management, Vol. 48 No. 1, pp. 7-24.

Nordberg, K. (2015), "Enabling Regional Growth in Peripheral Non-University Regions-The Impact of a Quadruple Helix Intermediate Organisation", Journal of the Knowledge Economy, Vol. 6 No. 2, pp. 334-356. 
Straus, F. (2010), "Netzwerkkarten - Netzwerke sichtbar machen", in Stegbauer, C. and Häußling, R. (Eds.), Handbuch Netzwerkforschung, VS Verlag für Sozialwissenschaften, Wiesbaden, pp. 527-538.

Witzel, A. (2000), “Das problemzentrierte Interview”, Forum: Qualitative Sozialforschung, Vol. 1 No. 1.
Wolf, C. (2006), "Egozentrierte Netzwerke. Erhebungsverfahren und Datenqualität”, Kölner Zeitschrift für Soziologie und Sozialpsychologie, No. 44, pp. 244-273. 